BULLETIN Bulletin hispanique

HISPANIQUE Université Michel de Montaigne Bordeaux

$120-2$ | 2018

Varia

\title{
Las ediciones de Príncipe perfecto y ministros ajustados de Andrés Mendo
}

Les éditions de Príncipe perfecto y ministros ajustados de Andrés Mendo The editions of the de Andrés Mendo's Príncipe perfecto y ministros ajustados

\section{Carlota Fernández Travieso}

\section{OpenEdition}

\section{Journals}

Edición electrónica

URL: https://journals.openedition.org/bulletinhispanique/6467

DOI: 10.4000/bulletinhispanique.6467

ISSN: $1775-3821$

Editor

Presses universitaires de Bordeaux

\section{Edición impresa}

Fecha de publicación: 10 diciembre 2018

Paginación: 419-440

ISBN: $979-10-300-0337-6$

ISSN: 0007-4640

\section{Referencia electrónica}

Carlota Fernández Travieso, «Las ediciones de Príncipe perfecto y ministros ajustados de Andrés Mendo», Bulletin hispanique [En línea], 120-2 | 2018, Publicado el 02 enero 2022, consultado el 08 enero 2022. URL: http://journals.openedition.org/bulletinhispanique/6467 ; DOI: https://doi.org/10.4000/ bulletinhispanique.6467 


\title{
Las ediciones de Principe perfecto y ministros ajustados de Andrés Mendo ${ }^{1}$
}

\author{
Carlota Fernández Travieso \\ Universidade da Coruña
}

Les éditions de Príncipe perfecto y ministros ajustados de Andrés Mendo

Cette étude a pour objet de recenser les éditions du livre d'emblèmes Príncipe Perfecto y ministros ajustados de Andrés Mendo (1608-1684) et de désigner celle qui devrait servir de base à l'édition critique d'une œuvre jusqu'ici trop négligée.

Mot-clés: Histoire éditoriale, Livres d'emblèmes espagnols, Miroirs de princes, XVII ${ }^{\mathrm{e}}$ siècle.

Este trabajo pretende establecer cuántas ediciones conocemos del libro de emblemas Príncipe perfecto y ministros ajustados de Andrés Mendo (1608-1684) y justificar cuál es la edición que debemos tomar como base para realizar una edición crítica de esta obra, que hasta este momento no ha recibido suficiente atención.

Palabras clave: Historia editorial, Emblemática hispánica, Espejo de príncipes, Siglo XVII.

The editions of the Andrés Mendo's Príncipe perfecto y ministros ajustados

This paper aims at establishing how many editions we know of the Emblems Book "Principe perfecto y Ministros Ajustados" by Andrés Mendo (1608-1684), and justify which edition we should use as a basis for a critical edition of this work, which until now did not receive enough attention.

Keywords: Editorial History, Spanish Emblems Books, Mirror for Princes, XVII Century.

1. Este trabajo se ha realizado en el marco del proyecto Biblioteca Digital Siglo de Oro 5 (BIDISO 5), con referencia: FFI2015-65779-P, financiado por el Ministerio de Economía y Competitividad del Gobierno de Espańa y el Fondo Europeo de Desarrollo Regional (FEDER) desde el 1-01-2016 hasta el 31-12-2019.

Bulletin Hispanique, Tome 120, n 2 - décembre 2018 - p. 419-440. 
Principe perfecto y ministros ajustados de Andrés Mendo, jesuita y predicador 1 de la corte de Felipe IV (1608-1684), figura entre las obras adscritas a la Emblemática hispánica que todavía no han sido objeto de una edición crítica ni estudiadas suficientemente. Esta falta de atención se debe, muy probablemente, al cuestionamiento de su originalidad en relación con los Emblemata centium regio politica de Juan de Solórzano Pereira (Madrid, 1653), obra con la que Mendo reconoce una fuerte relación. Nuestro autor ha sido calificado de plagiario y acusado del robo de los grabados por los estudiosos de la obra de Solórzano, a pesar de que la deuda de Mendo con este autor permanezca todavía a la espera de un estudio en profundidad ${ }^{2}$. Según Dimler, Mendo tomó de la obra de Solórzano las ideas, los conceptos y las citas sin hacer prácticamente cambios, sin embargo su estudio se reduce a los documentos XX, XXXI, XXXIII y LX. En contraposición con él, Rey Sierra, basándose en el hecho de que el concepto de originalidad en el Siglo de Oro era diferente del actual (se identificaba con la imagen aristofanesca de la abeja que libando de múltiples flores elabora su propia miel), defiende el tratado de Mendo como una obra per se. Esta investigadora pone el acento en las diferencias en la dispositio, que mejoran la perspectiva didáctica. Además, menciona que en el documento I de la edición de 1662 se suman, respeto a la edición de 1657, varias citas nuevas: Halicarnaso, Vitruvio, Causino o San Clemente. En el documento III aparecen también más nombres: Plutarco, Aristóteles o Alejandro de Alejandro. Según lo dicho por Rey Sierra, parece que Mendo, tal y como indica en la «Razón de la obra» de la edición de 1662, ha enriquecido el texto con «muchas erudiciones observadas con nuevo estudio». Dimler, sin embargo, pone en cuestión esta afirmación del autor ${ }^{3}$. En cualquier caso, el texto castellano merece ser fijado, ya que, cuando menos, tiene el mérito de haber trasladado las ideas de Solórzano al público general, alcanzando mayor difusión que el original latino.

Al hilo de las tareas de edición de esta obra, se han producido importantes avances en el conocimiento de la historia editorial de Principe perfecto $y$ Ministros ajustados, en los que se centra el presente trabajo.

2. Santiago Sebastián López, "Prólogo ", en Juan de Solórzano Pereira, Emblemas regiopolíticos, ed. Jesús María Gónzález de Zárate, Madrid, Ediciones Tuero, 1987, p. IX. Beatriz Antón Martínez, «Los Emblemata Centum Regio Politica de J. de Solórzano, o los cien ojos de Argo ", en Los días de Alción. Emblemas, Literatura y arte del Siglo de Oro, eds. Antonio Bernat Visitarini y John T. Cull, Palma de Mallorca, José Olañeta, Universitat de les Illes Balears, College of the Holy Cross, 2002, p. 51. Antón Martínez Beatriz y Chris Heesakkers, "Herederos de Alciato en Holanda y España: Adriano Junio (Emblemata, 1565) y Juan de Solórzano Pereira (Emblemata Centum Regio Politica, 1653)", Revista de filología clásica, no 16, 2002-2003, p. 145.

3. Richard G. Dimler, "Mendo's Principe Perfecto: A Historical and Textual Analysis of Documento XX ", en Emblem Scholarship: Directions and Developments: A Tribute to Gabriel Hornstein, ed. Peter M. Daly, Turnhout, Brepols Publishers, 2005, p. 117-125. Ana María Rey Sierra, «Mendo a la sombra de Solórzano Pereira », Lemir, n 4, 2000, [En línea]. [Consultado el 11 de julio de 2018]. Disponible en http://parnaseo.uv.es/lemir/revista/revista4/Rey/Rey.htm 


\section{EDICIONES REPERTORIADAS}

En su valiosa bibliografía sobre la emblemática hispánica, publicada en 1990, Pedro F. Campa, describe cuatro ediciones de Principe perfecto y ministros ajustados:

1. Lyon, 1642, por Horacio Boissat y George Remeus, para la que no se indica ningún ejemplar, únicamente menciona como fuente el repertorio de Praz.

2. Salamanca, 1657, por Diego Cosío.

3. Lyon, 1661, por Horacio Boissat y George Remeus / Claudio Bourgeat y Miguel Liétard, que Campa señala como la primera edición ilustrada.

4. Lyon, 1662, de nuevo por Horacio Boissat y George Remeus (en esta ocasión, sin la colaboración de Bourgeat y Liétard), que, según Campa, es la editio optima ${ }^{4}$.

Daly y Dimler, en su repertorio de libros de emblemas de jesuitas, señalaron la existencia de cinco ediciones de esta obra. La primera de ellas, Lyon 1642, la tomaron directamente del catálogo de Campa, sin señalar ningún ejemplar. Por lo demás, suman a las indicadas una quinta edición que denominan Lyon 1659, tomando la fecha de la dedicatoria, pues no constan en ella datos de edición. Nosotros preferimos denominarla:

5. [S.L.], [S.I.], [S.A.]'

En efecto, sobre la edición de 1642, Rey Sierra, había ya aclarado que se trataba de una edición fantasma. Un error tipográfico (la confusión de un 4 con un 6), perpetrado en el Catálogo de libros españoles o relativos a España antiguos y modernos puestos en venta a los precios marcados de García Rico, se fue transmitiendo de una bibliografía a otra. Palau tomó información de este trabajo para su Manual del Librero Hispano Americano y, aunque se había corregido y explicado el error en su segunda edición, la referencia a la edición de 1642 pasó de Palau al repertorio de Praz (tanto a la primera como a la segunda edición, de 1939 y 1964 respectivamente), de donde la toma Campa ${ }^{6}$.

4. Pedro F. Campa, Emblemata Hispanica. An Annotated Bibliography of Spanish Emblem Literature to the Year 1700, Durham, London, Duke University Press, 1990, pp. 54-55.

5. Peter M. Daly y Richard G. Dimler, Corpus Librorum Emblematum. Jesuit Series, vol. 4, Toronto, University of Toronto Press, 2004, pp. 71-74.

6. Eugenio García Rico, Catálogo de libros españoles o relativos a España antiguos y modernos puestos en venta a los precios marcados por García Rico y Cia, Madrid, Librería Universal de Ocasión, 1916, p. 684. Antonio Palau y Dulcet, Manual del librero hispano-americano: inventario bibliográfico de la producción cientifica y literaria de España y de la América Latina desde la invención de la imprenta hasta nuestros días, con el valor comercial de todos los artículos descritos, $1^{a}$ ed., vol. V, Barcelona, Librería Anticuaria, 1923-1927, p. 151. Antonio Palau y Dulcet, Manual del librero hispano-americano: bibliografía general española e hispano-americana desde la invención de la imprenta hasta nuestros tiempos con el valor comercial de los impresos descritos por Antonio Palau y Dulcet, revisado y añadido por Agustín Palau, 2a ed., vol. IX, Barcelona, Librería Palau, 1956, pp. 32-33. Mario Praz, Studies in Seventeenth-Century Imagery. Second edition considerably increased, 2a ed., Roma, Edizione di Storia e Letteratura, 1964, pp. 420-421. 
La primera edición sería, por tanto, la impresa en Salamanca en 1657, sin ilustraciones. Aunque hoy resulta extraño que un libro concebido para llevar imágenes se imprima sin ellas, en España muchos libros de emblemas se imprimieron sin las picturae. Como explica López Poza, en el complejo proceso de producción de este tipo de obras intervenían el emblemista, el artista que dibujaba los conceptos que el autor deseaba plasmar, el grabador que abría las planchas, el editor o librero que pagaba la cara edición y el impresor. Para la elaboración de libros de emblemas se requería, pues, de ingentes medios materiales y humanos, que no siempre eran fáciles de encontrar ${ }^{7}$. La posterior inclusión de las picturae y las modificaciones del texto por parte del autor (ya derivadas de la necesidad de integrar las imágenes en la explicación, ya de la voluntad de Mendo de enriquecer el texto con esas «erudiciones observadas con nuevo estudio» que menciona en la «Razón de la obra» de la «segunda impresión») justifica que Campa no señale la prínceps como editio optima, pero ¿qué le hizo decantarse por la edición impresa en 1662, en lugar de la impresa un año antes, en 1661? Es además necesario considerar la edición sin datos de publicación que Campa desconocía, ¿será preferible basarse en ella para realizar nuestra edición crítica?

\section{LOCALIZACIÓN DE EJEMPLARES}

Para localizar ejemplares de las diferentes ediciones de la obra se recurrió al Catálogo DEBOW, publicado por López Poza y Fernández Vales; el Karlsruhe Virtueller Katalog (KVK), un metabuscador que permite realizar búsquedas simultáneas en múltiples catálogos colectivos de bibliotecas de distintos países, en los catálogos de distintas bibliotecas nacionales o en las principales plataformas de textos electrónicos; el Catálogo colectivo del patrimonio bibliográfico español y el Catalogue Collective de France, dos grandes ausentes en el KVK en los que, al tratarse de una obra en español que se imprimió en Francia, interesaba hacer búsquedas ${ }^{8}$. La abundancia de testimonios de las ediciones de Salamanca 1657 y Lyon 1662 en bibliotecas con fondo antiguo, que con frecuencia permiten acceso a copia digital on-line, contrasta con la escasez de ejemplares de las ediciones de 1661 en las que aparecen los nombres

7. Sagrario López Poza, «Los libros de emblemas y la imprenta », Lectura y signo, n 1, 2006, pp. 178-179.

8. Me refiero al recurso digital DEBOW (Digital Emblem Books on Web), que de su versión en pdf de 2013 <https://www.bidiso.es/upload/estaticas/file/CatalogoDEBOW.pdf> ha migrado a una base de datos que permite su constante actualización y que hallamos disponible en http://debow.bidiso.es [Consultada el 11 de julio de 2018].

Karlsrube Virtueller Katalog (KVK), [En línea]. [Consultado el 11 de julio de 2018]. Disponible en <https://kvk.bibliothek.kit.edu>. Catálogo Colectivo del patrimonio bibliográfico español, [En línea]. [Consultado el 11 de julio de 2018]. Disponible en <http://catalogos.mecd. es/CCPB/ccpbopac>. Catalogue Collectif de France [En línea]. [Consultado el 11 de julio de 2018]. Disponible en: <https://ccfr.bnf.fr>. 
de cuatro costeadores y la edición sin datos de publicación mencionada por Daly y Dimler 9 . De la edición de 1661, se localizaron, por este medio, sólo 2 ejemplares, uno en Biblioteca universitaria de Glasgow, parte de la Stirling Maxwell Collection, (Sp. Col. S. M. 1391) y otro en la Biblioteca Nacional de Madrid (R/3032). De la edición sin datos de impresión, se encontró únicamente un ejemplar en la Biblioteca Nacional de Madrid (R/38475). En su repertorio, Campa menciona la existencia de otros ejemplares de la edición de 1661, en la Biblioteca Universitaria de Leiden y la British Library. Daly y Dimler refieren también ejemplares de la edición de 1661 en la British Library (80007 cc. 17) y la biblioteca de la Duke University y de la edición sin datos de publicación en la Bibliotèque Nationale de France (E475 y E1011) y en el Zentralinstitüt für Kugstgeschichte de Munich (SB 242/15). Sin embargo, en los catálogos en red de estas instituciones no consta ninguno de ellos. Tras intercambiar correspondencia sobre esta cuestión con el personal de estas bibliotecas (a quienes agradezco que hayan tenido a bien comprobar la información, enviando incluso las fotografías oportunas y revisando los catálogos antiguos), se puede afirmar que, en todos estos casos, parece que ha habido confusiones con ejemplares de las ediciones de 1657, de 1662 y de la traducción al italiano del Principe perfecto publicada en 1816 que se conservan en esas bibliotecas.

\section{Cotejo}

Para el cotejo de las distintas ediciones de Príncipe perfecto y ministros ajustados me he dirigido a la Biblioteca Nacional de España, donde además de los ejemplares mencionados (uno de los dos ejemplares de 1661 localizados y el único sin datos de publicación del que he podido comprobar su paradero) se custodian ejemplares de las ediciones de 1657 y 1662. Por otra parte, he

9. De la edición de 1657, he manejado el ejemplar 3/40065 de la Biblioteca Nacional de España y, además, he podido observar en formato digital el ejemplar ANT 2.024 de la Biblioteca Pública de Burgos digitalizado por la Biblioteca Virtual de Castilla y León y los preliminares de un ejemplar custodiado en la Biblioteca de la Universidad de Salamanca, accesibles a través de Internet en el repositorio de esta institución. De la edición de 1662, he manejado los ejemplares de la Biblioteca Nacional de Espańa 3/22924 (utilizado para el cotejo) y ER/3885 y los volúmenes Rés 340882 y SS SJ 170/3 de la Bibliothèque Municipale de Lyon (que además se hallan en Google Books); así mismo, he podido observar en formato digital otros 4 ejemplares (de la Biblioteca Nazionale di Napoli y de la Universidad Complutense de Madrid, también digitalizados por Google Books; de la biblioteca de la University of Illinois en UrbanaChampaing, recogido en la web del proyecto Emblematica Online, y de la Stadtbibliothek Zurich, reproducido por la casa IDC y accesible en línea en las web del grupo de trabajo Biblioteca de Emblematica de la Università degli Studii di Bergamo y del proyecto BIDISO); los preliminares de un ejemplar (esta vez de 1662) custodiado en por Biblioteca de la Universidad de Salamanca, accesibles en el repositorio de esta institución y los preliminares y el cuadernillo con la signatura ff de los ejemplares Sp. Coll. BD16-f.5 y Sp. Coll. S.M. 1391.1 de la Biblioteca de la Universidad de Glasgow. 
obtenido información y las fotografías precisas del ejemplar de 1661 custodiado en la Biblioteca Universitaria de Glasgow gracias a Pedro Germano Moraes Cardoso Leal, investigador de la Universidade Federal de Río de Janeiro, que hasta hace poco trabajaba en la Universidad de Glasgow, a quien agradezco enormemente su ayuda para realizar las comprobaciones necesarias.

$\mathrm{Al}$ iniciar el cotejo de los tres ejemplares (el R 3032 de 1661, el 3/22924 de 1662 y el R/38475 sin datos editoriales), se observó el tamaño, las signaturas, la numeración, las tipografías utilizadas y la presencia y tipo de grabados. El ejemplar que no tiene datos de impresión es un poco más corto, pero esto se debe a que al guillotinarlo para la encuadernación redujeron los márgenes superior e inferior, la caja es del mismo tamańo que la de los otros ejemplares. Los tres volúmenes comparten la misma secuencia colacional:

$4^{0} .-\dagger^{4} \dagger^{4} \dagger_{*}^{4}{ }_{* * *}^{4}{ }_{* * *}^{4}{ }_{* * * *}^{2} A-Z^{4} a-g^{4}$ aa-gg ${ }^{4}$ aaa $-0 o o^{4} .-22$ h. 1-184 p., 1-56 p., 1-56 p., 1-111[112] p.- L. red. y curs.- Con grab. Calc.- 56,5 pliegos.

Sin embargo, al abrir los ejemplares, nos encontramos con tres portadas diferentes:

a) La de 1661 (figura 1), realizada en blanco y rojo, con la marca tipográfica de Bourgeat y Liétard, una imagen de la anunciación con sus iniciales en el centro, y los nombres de los cuatro costeadores que corrieron con los gastos de su producción. A esta sigue una dedicatoria de uno de ellos, Claudio Bourgeat, a la reina de Francia.

b) La de 1662 (figura 2), en negro, con la marca tipográfica de Boissat y Remeus, una imagen de una embarcación con el mote ingenium superat vires y sus iniciales en el medio, y sólo los nombres de Boissat y Remeus. A esta sigue una dedicatoria de Andrés Mendo, fechada en Salamanca a 15 de noviembre de 1659, dirigida a don Alonso Pérez de Guzmán.

c) Y una portada en la que no constan datos de edición, muy diferente a las otras dos, con una disposición diversa del texto, sin imagen alguna y sin mencionar el "Añadido de las Estampas» o que sea «En emblemas» (figura 3). Esta primera hoja está pegada sobre papel original del libro. En la página siguiente se observa la misma dedicatoria del ejemplar de 1662 consultado, fechada en 1659.

A continuación, se cotejó línea a línea y página a página los tres volúmenes y se aplicó la prueba de la diagonal. Esta prueba es una técnica que Jaime Moll solía utilizar para comprobar si dos ejemplares similares eran o no parte de una misma edición. Se trata de situar una regla a partir de los mismos puntos en la misma página de cada uno de los ejemplares que se quieren cotejar. Si la diagonal trazada corta los reglones exactamente por el mismo sitio, se puede afirmar que se trata de la misma composición tipográfica. La profesora Mercedes Fernández Valladares, de la Universidad Complutense, me ha transmitido esta técnica y ayudado a aplicarla a los ejemplares que nos ocupan. Le agradezco enormemente que haya tenido a bien compartir conmigo algunos de sus muchos conocimientos sobre bibliografía material y análisis de ediciones. 
Entre los mencionados ejemplares de la edición de 1661 y 1662 custodiados en la BNE, además de las diferencias ya mencionadas (de portada y dedicatoria), hay solo algunas leves variantes en la composición del primer cuadernillo (el marcado con la signatura $\dagger$ ) y en el cuadernillo que contiene los documentos LVII y LVII (el marcado con la signatura ff). En la línea 21 de la página sign. $\dagger 3$ r., hacia el final, en la edición de 1661, la palabra norte está escrita con mayúscula, mientras que en la edición de 1662 está con minúscula. Las líneas 18,19 y 20 de la página sign. $\nmid 4$ r. de la edición de 1661 acaban en «prima de», «nue-» $\mathrm{y}$ «Dada en» respectivamente, mientras que en la edición de 1662 terminan en "prima de Ca-», "nuestra» y "Dada en Sala-». Estas variantes no se encuentran en ninguno de los otros ejemplares que hemos podido observar, tampoco en el otro ejemplar de 1661 custodiado en la Universidad de Glasgow. La sustitución del tipo con la n minúscula por un tipo con la $\mathrm{N}$ mayúscula parece tratarse simplemente de una corrección en prensa. Las alteraciones en la página sign. $\$ 4$ r. parecen deberse a una recomposición de esos puntos concretos tras descabalarse accidentalmente parte de la forma en algún momento de la producción, pues no hallamos otra razón que pueda motivar estos cambios. Más adelante, en el ejemplar de 1661 de la BNE, en el mencionado pliego $\mathrm{ff}$, encontramos intercambiadas las páginas 42 y 43 con las páginas 46 y 47. Asimismo, nos percatamos de que también se han intercambiado las picturae de los documentos LVII y LVIII y de que encima de ellas se ha pegado un recorte con la pictura correcta. Parece que la primera plana del pliego ff se imprimió invertida, mientras la retiración se mantuvo en el sentido correcto. A consecuencia de este error en el casado, se produjo otro fallo en la disposición de las ilustraciones. Tras pasar por la prensa, los pliegos con grabados calcográficos debían ir al tórculo, pues estos requerían de mayor presión que el texto. Los impresores, que inicialmente ignoraban u olvidaron el percance de la plana invertida, dispusieron las ilustraciones en orden, por lo que se imprimieron en las páginas equivocadas. El grabado del documento LVII, el del lema "Pareto legi qvis qvis legem tuleris", se colocó en la página 48, donde estaba el texto que correspondía al documento LVIII, pues ocupaba en el pliego el espacio reservado a la que sería la cuarta página del cuadernillo tras ser doblado dos veces. El grabado del documento LVIII, el del lema "Regis praesentia velox», se colocó en la página 44, donde estaba el texto que correspondía al documento LVII, pues ocupaba en el pliego el espacio reservado para la que sería la octava y última página del cuadernillo (figuras 4 y 5). El ejemplar SJ SS 170/3 de la Bibliothèque Municipale de Lyon presenta también variantes en este cuadernillo. El grabado con el lema "Regis praesentia velox» se imprimió dos veces, como imagen del documento LVII y del documento LVIII, lugar que le corresponde. Sobre la segunda de las imágenes, en el documento LVIII (página 48), se ha pegado un recorte con el grabado con el lema "Pareto legi qvis qvis legem tuleris» (figura 6). Parece que, al tratar de corregir la repetición de imágenes, se ha cometido un nuevo error, pues no se pegó el recorte en el sitio oportuno. El resultado es una inversión de 
las imágenes: en el documento LVII se observa la pictura del documento LVIII y en el documento LVIII, la del documento LVII, bajo ella estaría la correcta. Las páginas de este ejemplar están, sin embargo en el orden correcto. Quizá, los impresores advirtieron que la primera plana del folio en cuestión estaba girada y corrigieron este error, pero la confusión generada con el orden de las imágenes se impuso en algún caso más. No hemos encontrado estas variantes en el cuadernillo ff de los otros ejemplares observados, tampoco en ejemplar de 1661 que se conserva en Biblioteca Universitaria de Glasgow, en el que con respeto al ejemplar de 1662 de la BNE cotejado cambia únicamente la portada y la dedicatoria.

Por otro lado, la portada del ejemplar sin datos de edición resulta ser idéntica a la de la edición publicada en Salamanca en 1657. Al comparar esta portada con la de la editio prínceps, observamos que la diagonal corta cada uno de los renglones por el mismo sitio y que los perfiles de varios tipos estaban desgastados en los mismos lugares (figura 7). Me refiero al borde de la «T» de la palabra "Theulugia» (línea 12), de la «d» en «da Escritura» (línea 13) y, aunque menos evidentes, también al perfil de la «s» en «sición» (línea 11) y de la «S» en "Salamanca» (línea 14). La portada del ejemplar sin datos de edición y la de la edición impresa por Diego Cosío son la misma composición; aunque, más allá de la portada, el cotejo línea a línea y las diagonales revelan que no existen otras diferencias entre este ejemplar y el fechado en 1662. Parece que a un ejemplar de 1662, presumiblemente mútilo de portada, se la añadió la portada de un ejemplar publicado en 1657. Este tipo de manipulación es frecuente en ejemplares que, como este, que ostenta el exlibris de la biblioteca de Antonio Cánovas del Castillo, han circulado en ámbitos bibliófilos.

Resta mencionar que a algunos ejemplares manejados corresponde una secuencia de signaturas y numeración de páginas/folios ligeramente diferente:

$4^{\mathrm{o}} .-\dagger^{4} \dagger^{4} \mathrm{~A}-\mathrm{Z}^{4} \mathrm{a}-\mathrm{g}^{4} \mathrm{aa}-\mathrm{gg}^{4}$ aaa-ooo ${ }_{*}^{4}{ }_{* * *}{ }^{4}{ }_{* * *}{ }^{4}{ }_{* * * *}^{2} .-8$ h. 1-184 p., 1-56 p., 1-56 p., 1-111[112] p., 14 h.- L. red. y curs.- Con grab. Calc.- 56,5 pliegos.

Este es el caso del ejemplar ER/3885 de la BNE o de los ejemplares conservados en la Biblioteca Universitaria de Glasgow, el Sp. Coll. S.M. 1391, el Sp. Coll. BD16-f.5 y el Sp. Coll. S.M. 1391.1. Esta particularidad se debe a que en ellos, en las reencuadernaciones sucesivas o particulares de cada ejemplar, el "Índice de sentencias y cosas más notables» se ha pasado al final, lugar que le corresponde al hacer coincidir los reclamos ${ }^{10}$. Con este cambio, además, el colofón queda en la última página. Frente a ellos, en los tres ejemplares de la BNE cotejados, este índice se encuentra entre los preliminares, tras el «Índice de los documentos» y antes del inicio de la obra propiamente dicha con el documento I.

10. El ejemplar de la Biblioteca Nacional contiene una nota que indica que ha sido reencuadernado en 1981. Los ejemplares S.M. 1391 y S.M. 1391.1 de la Biblioteca Universitaria de Glasgow se encuadernaron de nuevo en siglo XIX para Sir Stirling Maxwell. 


\section{UN DOCUMENTO REVELADOR}

La edición lionesa del Principe perfecto y ministros ajustados de Andrés Mendo se vio afectada por un desacuerdo entre sus costeadores. Así lo apunta un documento titulado Response de Sr Claude Bourgeat demandeur, Au factum que Horace Boissat, et les deputez de ses creanciers ont publiés depuis que le procez a esté mis sur le bureau, au rapport de Monsieur Charrier, impreso hacia 1670 en Lyon (figura 8) ${ }^{11}$. Este documento de 14 páginas en tamaño $4^{\circ}$ es un Factum o mémoire judiciaire, un panfleto en el que una de las partes implicadas en un proceso judicial, en ese caso el demandante, Claude Bourgeat (uno de los editores de la edición lionesa del Principe perfecto) expone para los jueces los hechos. Con este documento se da respuesta a un factum previo del demandado, Horace Boissat (otro de los editores de la segunda edición de la obra de Mendo e impresor de la misma) y sus acreedores. La lectura de este documento nos revela que las sociedades Bourgeat-Lietard y Boissat-Remeus firmaron dos acuerdos para imprimir conjuntamente una serie de libros de autores españoles, por los que repartirían gastos y ejemplares a la mitad. El Príncipe perfecto de Andrés Mendo estaba entre los libros sujetos al segundo de los acuerdos, firmado el 20 de diciembre de 1660, por el que estas sociedades se comprometieron a que durante tres años imprimirían juntos todos los libros de autores españoles que Bourgeat entregase. Boissat se encargaba de la impresión y Bourgeat actuaba como agente viajando a Espańa para conseguir acuerdos con los autores y traer manuscritos y, en algunas ocasiones, también a París, para conseguir privilegios del rey. Remeus fue con él en alguno de estos viajes a Espańa, pero, según Bourgeat, el socio de Boissat no tenía los contactos necesarios ni era capaz de negociar porque no sabía ni español ni latín, era él quien ponía toda la «industria». Sin embargo, Boissat y Remeus no respetaron estos acuerdos, negaron a Bourgeat y Liétard su mitad de los libros y no pusieron el nombre de estos en la portada, por lo que fueron demandados. Es posible que Boissat, acuciado por sus crecientes deudas (sabemos gracias a los estudios de Marie Rémilleux que se declaró en bancarrota en 1669), quisiera sacar mayor provecho de las obras impresas por su taller, dejando por ello a Bourgeat sin su parte. Según relata esta investigadora francesa, citando como fuente un documento hallado en los Archives Municipales de Lyon, Boissat menciona como causa de su bancarrota la escasa atención que Remeus ponía a sus gastos en sus viajes a países extranjeros, que no proporcionaban beneficio alguno; la peste en Alemania y la guerra en Francia, lugares donde tenía acuerdos para la venta de sus libros, y la pérdida de varios libros enviados a

11. Response de Sr Claude Bourgeat demandeur, Au factum que Horace Boissat, et les deputez de ses creanciers ont publiés depuis que le procez a esté mis sur le bureau, au rapport de Monsieur Charrier, Lyon, [S. I.], [S. A.], [En línea]. 7 de noviembre de 2013 [Consultado el 11 de julio de 2018]. Disponible en <https://books.google. es/books?id=C_kGcn4k4gAC\&printsec $=$ frontcover $\&$ hl l=es \&source=gbs_ge_ summary_r\&cad $=0 \# \mathrm{v}=$ onepage $\& \mathrm{q} \& \mathrm{f}=\mathrm{false}>$. 
España, que al parecer fueron robados por los turcos ${ }^{12}$. Una sentencia de 1669 condenó a Boissat a dar cuenta de sus gastos para realizar estas impresiones, con la finalidad de que el juez pudiera determinar qué indemnización correspondía a Bourgeat. Boissat proporcionó entonces un Factum con sus cuentas, del que el presente texto es respuesta. En él, Bourgeat rechaza totalmente la exposición de los hechos por parte de Boissat: no está de acuerdo con el precio del papel, con el precio de venta que fijó Boissat para los libros, con el precio del transporte de los libros, con que le siga pidiendo intereses por haber adelantado una parte del dinero en uno de los casos. Bourgeat cree que deben pagarle intereses a él, por su trabajo para conseguir las obras y por los gastos que tuvo para alcanzar acuerdos con los autores espańoles y conseguir algunos de los privilegios. Además, Bourgeat acusa a Boissat de dar sólo información sobre 15 libros, ocultando información sobre 9 más. Entre las obras que Boissat oculta en su informe al juez están varios textos de Mendo, el De ordinibus militaribus, que según Bourgeat fue entregada al incio de la sociedad, en 1660, junto con el texto del Príncipe perfecto, y sufrió un retrasó en la impresión a mala fe para publicarla una vez terminado el plazo del acuerdo (en 1668); el Statera opinionum benignarum in controversis moralibus (que Boissat y Remeus publicaron en Lyon en 1666), el De iure académico (en 1668) y el Bullae Sanctae cruciate elucitate (en 1668). Junto a este factum Bourgeat proporcionó sus propias cuentas; un documento hecho en Madrid por el que Boissat y Remeus no quisieron consentir que Bourgeat imprimiera por su cuenta una serie de obras de Mendo, prometiendo imprimirlas ellos mismos, y una serie de cartas que Mendo envió a Bourgeat en 1660. Siguiendo las indicaciones de los trabajos de Marie Rémilleux hemos intentado localizar estos documentos en los Archives Municipales de Lyon, aunque, lamentablemente, sin éxito. Marie Rémilleux menciona que los documentos relativos a la bancarrota de Horace Boissat (entre los que se encontraban tres informes sucesivos de los gastos ocasionados por quince impresiones de autores españoles realizadas entre 1661 y 1664, la proporcionada por Boissat, la proporcionada por Bourgeat y la definitiva, la establecida en 1675 por el librero Laurent Anisson) se hallan en los Archives Municipales de Lyon; sin embargo no hemos encontrado estos documentos en las carpetas mencionadas por esta investigadora (la FF 143 y FF 163, que en la actualidad corresponden con la FF 256 y el FF 273). Aunque se han revisado otros muchos legajos de este archivo y de los Archives Departamentales du Rhône, no he logrado localizar ninguno de estos informes ni otros documentos relativos a la causa entre Bourgeat y Boissat que esperaba se encontraran junto a ellos ${ }^{13}$.

12. Marie Rémillieux, "À propos d'une faillite libraire ", en Nouvelles études lyonnaises, ed. Roger Chartier, Genève, Droz, 1969, pp. 79-91.

13. Además, en el trabajo citado previamente la investigadora francesa hace referencia a los documentos mencionados en un estudio inédito que hemos consultado en la Bibliothèque Municipale de Lyon (signatura MSD 0023): Marie Rémilleux, Études sur quelques libraires et un imprimeur lyonnais au XVII siècle. Diplôme Principal d'Études Superieures sous la direction de R. Gascon et M. H. J. Martín, 1966. Por otra parte, gracias al Factum que hemos localizado, 


\section{Conclusiones}

En definitiva, los ejemplares cotejados en la Biblioteca Nacional de España, aunque ostenten en su portada datos de publicación diferentes, pertenecen a la misma edición. Como es sabido, en la época de la imprenta manual, incluso cuando se ha intentado copiar a plana y renglón una edición anterior, resultaba imposible no introducir diferencias en la composición ${ }^{14}$. Los tres ejemplares, con las excepciones referidas, que afectan a lo sumo sólo a dos cuadernillos, son por lo demás idénticos. Así lo avalan el cotejo página a página y línea a línea y la prueba de las diagonales. Considerando, además, que la edición lionesa de 1642 es una edición fantasma, podemos afirmar que de Príncipe perfecto y ministros ajustados de Andrés Mendo se publicaron únicamente dos ediciones. La primera, sin imágenes, fue impresa en Salamanca por Diego Cosío en 1657. La segunda, que incorpora los grabados que Roberto Cordier elaboró para la obra de Solórzano, fue impresa en Lyon con la participación de las sociedades: Boissat-Remeus y Bourgeat-Liétard, muy probablemente en 1661. De esta segunda edición hay dos emisiones. La primera emisión, A, en la que consta 1662 como ańo de publicación, los nombres solo de dos de los cuatro libreros y la dedicatoria «original» del propio Mendo, fue la primera en ver la luz. Forman parte de la emisión A los ejemplares 3/22924 y ER/3885 de la Biblioteca Nacional de España, Sp. Coll. BD16-f.5 y Sp. Col. S. M. 1391.1 de la Biblioteca Universitaria de Glasgow o SS SJ 170/3 y Rés. 340882 de la Bibliothèque Municipale de Lyon. Así mismo, el ejemplar R/38475 de la Biblioteca Nacional, que por estar manipulado tiene una portada diferente, sin datos de edición, se asimila claramente a la emisión A. A la vista del Factum que hemos localizado, mi suposición es que de las disposiciones del juez surgió otra emisión, B. Boissat fue obligado a dar a Bourgeat al menos una parte de los ejemplares que aún conservaba. En ellos se cambió la portada para que constaran los nombres de los cuatro costeadores y, seguramente, la verdadera fecha de impresión: 1661. Probablemente Boissat y Remeus hicieron constar el año de 1662 para hacerla pasar como edición posterior, solo a cargo suyo. Además, se sustituye la dedicatoria del autor por una de Claudio Bourgeat a la reina de Francia, quizá en agradecimiento por la resolución del pleito. Sólo hemos localizado dos ejemplares que hacen parte de esta emisión: el R 3032 de la Biblioteca Nacional y el Sp. Col. S. M. 1391 de la Biblioteca Universitaria de Glasgow. Boissat terminaría por entregar pocos ejemplares a Bourgeat, lo que explicaría la escasez de testimonios fechados en 1661.

se confirman nuesros cálculos de que cada ejemplar tenía 56 pliegos y medio y tenemos noticia de que la tirada del Príncipe perfecto producida en Lyon constaba de 1.150 ejemplares y de que fue Bourgeat quien al inicio de la sociedad proporcionó, junto al original y el privilegio real, las figuras (expresión con la que probablemente se refiere a las planchas de los grabados que Roberto Cordier abrió para los Emblemata centium regio-politica de Solórzano Pereira).

14. Jaime Moll, "Problemas bibliográficos del libro del Siglo de Oro ", Boletín de la Real Academia Española, no 59, 1979, p. 49-107, [En línea]. [Consultado el 11 de julio de 2018]. Disponible en: <http://www.cervantesvirtual.com/nd/ark:/59851/bmcvd7c6>. 
En algunos ejemplares de esta segunda edición se produjo un error en el casado del cuadernillo sign. ff y/o en la disposición de las ilustraciones, lo que ha dado lugar a varios estados: uno en el que se intercambia el orden de las páginas 42 y 43 con las páginas 46 y 47 y las imágenes de los documentos LVII y LVIII, del que es muestra el ejemplar R/3032 de la Biblioteca Nacional; otro en el que se repite el grabado que corresponde documento LVIII en el documento LVII, caso del ejemplar SS SJ 170/3 de la Bibliothèque Municipale de Lyon, y otro sin estos errores, del que son ejemplo los restantes testimonios de los que hemos hecho mención. Existen otros dos estados, por corrección de una pequeña errata en prensa ( $\mathrm{n} / \mathrm{N}$ en «Norte») y recomposición de las cinco últimas líneas de la Licencia del ordinario, en la hoja sign. $\uparrow 4 \mathrm{r}$, quizá porque se descabalaron en la forma. En el ejemplar BNE R/3032 (y únicamente en éste de entre todos los consultados) aparece la palabra Norte con mayúscula y una composición de la hoja sign. $\uparrow 4 \mathrm{r}$ ligeramente diferente.

Así mismo, hemos detectado otras particularidades: en el ejemplar R/3032 de la Biblioteca Nacional de España se pegaron unos recortes con las imágenes correctas encima de las imágenes que se habían dispuesto erróneamente; en el ejemplar SJ SS 170/3 de la Bibliothèque Municipale de Lyon se pegó, erróneamente, un recorte del grabado que corresponde al documento LVII sobre el del documento LVIII; en BNE ER/3885 o en los ejemplares conservados en la Biblioteca Universitaria de Glasgow, el Sp. Coll. S.M. 1391, el Sp. Coll. BD16-f.5 y el Sp. Coll. S.M. 1391.1, se encuadernó el «Índice de sentencias y cosas más notables» en otro orden y al ejemplar BNE R/38475, con exlibris de Cánovas del Castillo, al que posiblemente le faltaba la portada, se le añadió la de la primera edición.

La variación de los datos de publicación en las portadas de las dos emisiones y la manipulación del ejemplar BNE R/38475 habrían dado lugar a la proliferación de ediciones en las bibliografías que atendían a esta obra.

La editio optima es la segunda edición, en la que se añaden las imágenes y Mendo introduce modificaciones finales en el texto. Salvando en ella los errores producidos en el proceso de impresión que hemos mencionado, recuperando los nombres de los cuatro costeadores y la fecha de 1661 (que a mi entender es la fecha más verídica, ya que consta en los ejemplares donde se corrigen otros datos de edición), podemos tomar la edición de Lyon (la única que se produjo en esta ciudad) como base para nuestra edición crítica, que esperamos que muy pronto pueda ver la luz. 


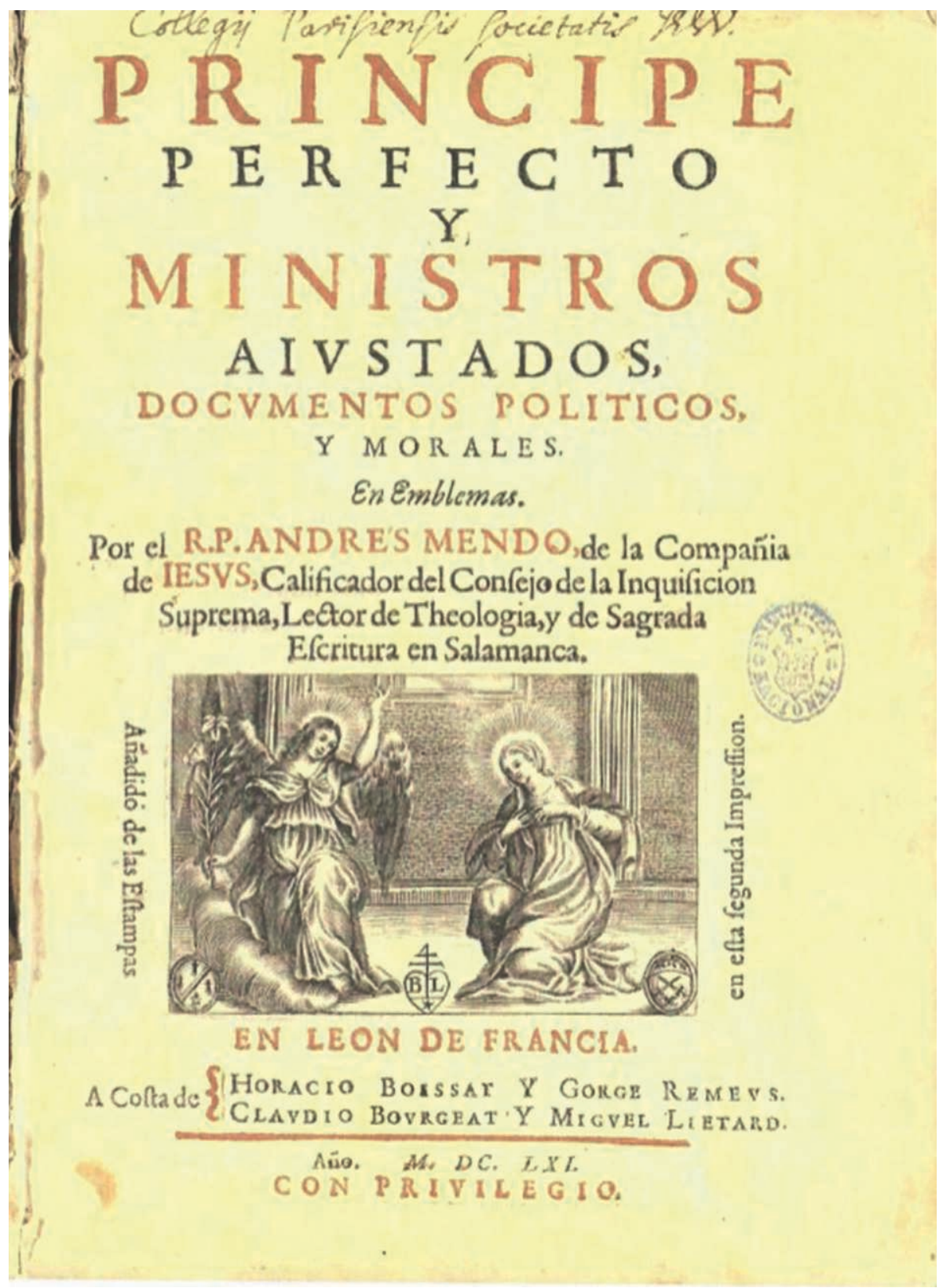

Fig.1. - Portada del ejemplar BNE R 3032 de 1661 


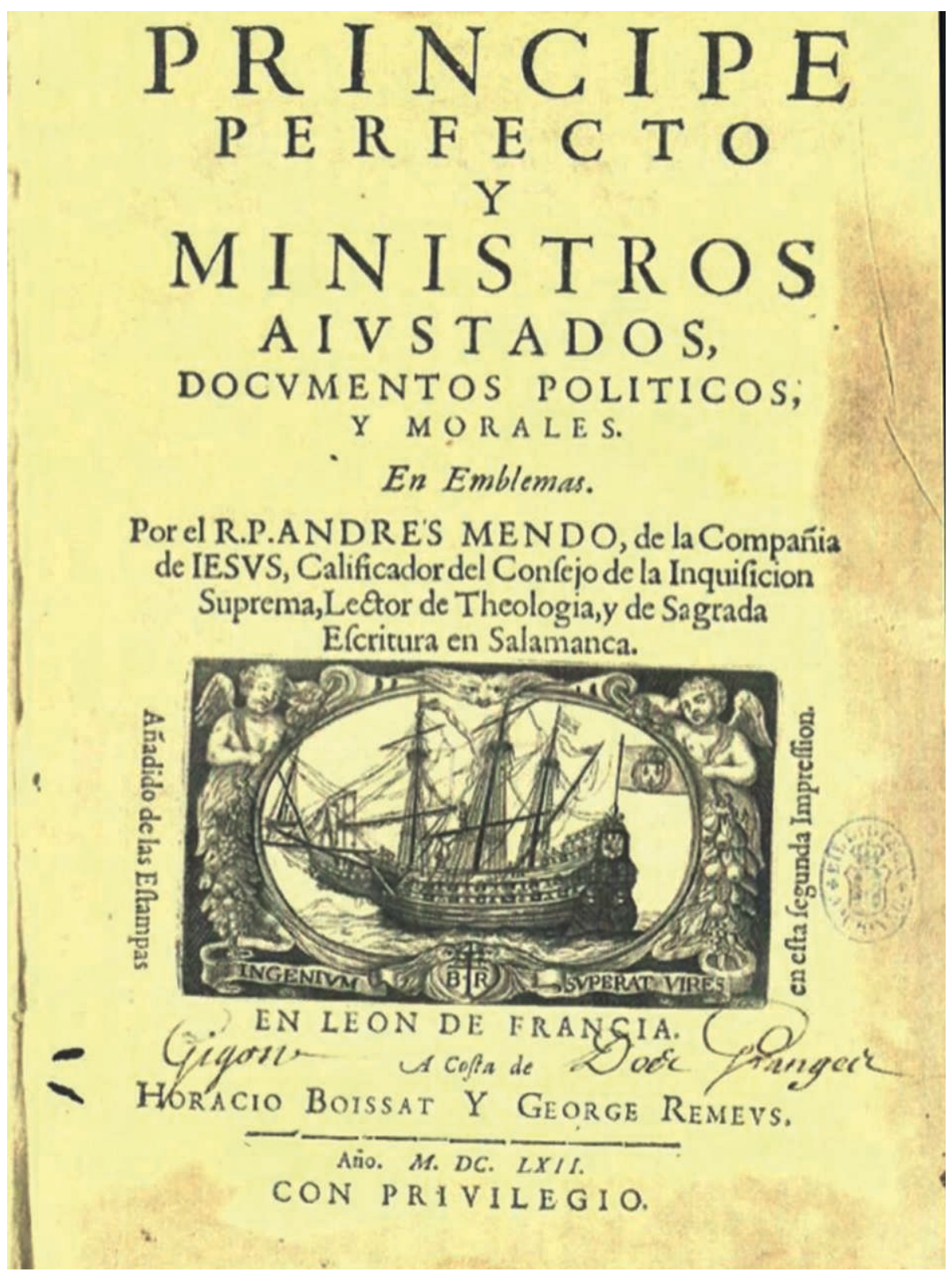

Fig. 2. - Portada del ejemplar BNE 3/22924 de 1662 


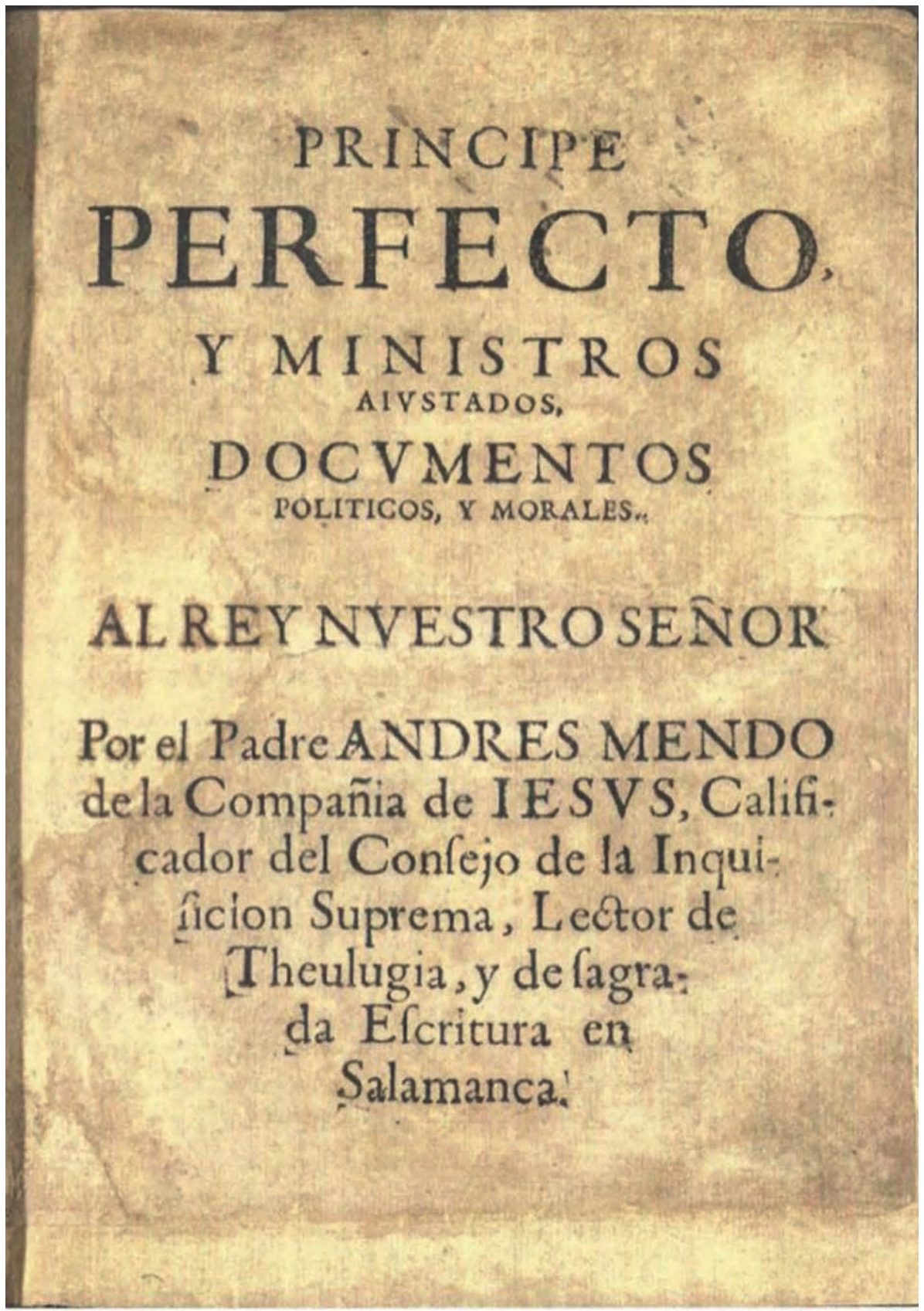

Fig. 3.- Portada del ejemplar BNE R/38475, sin datos editoriales 


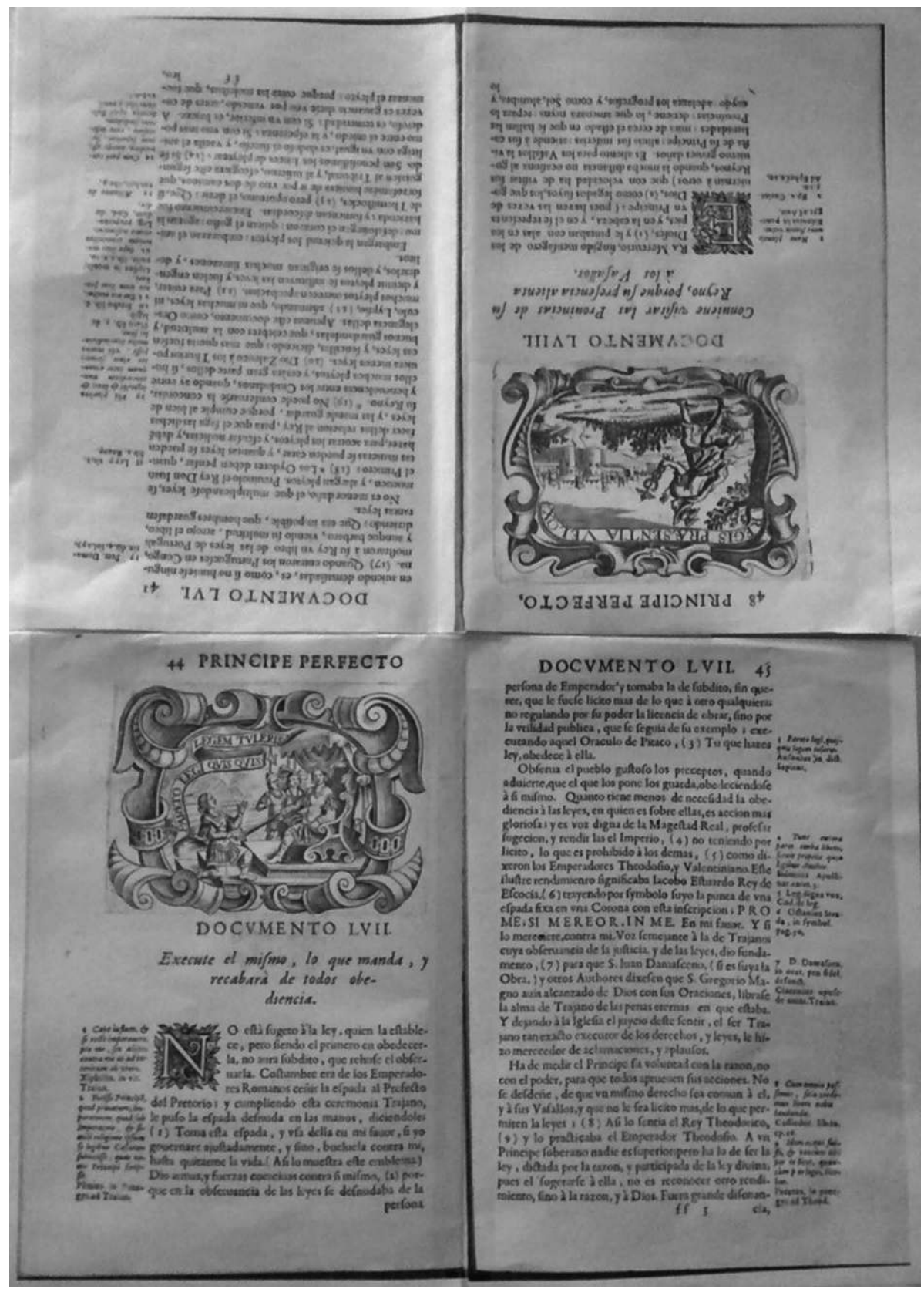

Fig. 4. - Disposición del pliego ff en el ejemplar de la edición de 1661 de la BNE sin plegar 

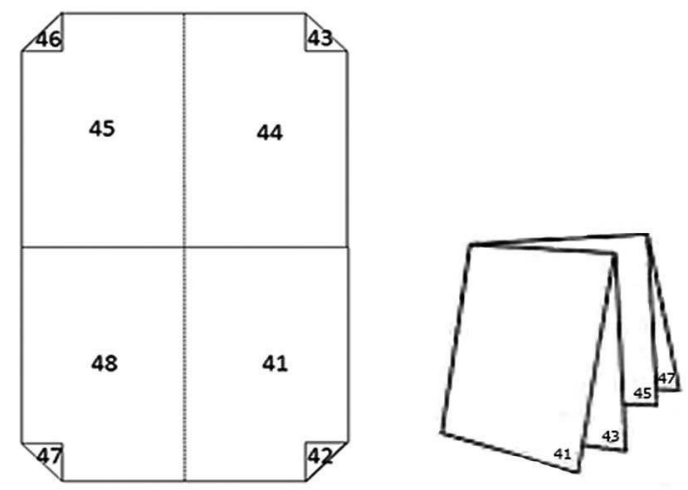

Fig. 5. - Frente a la disposición del pliego ff del ejemplar de la edición 1661 consultado en la $\mathrm{BNE}$, véase aquí cual sería la disposición correcta. Los números en centro de cada rectángulo son los de las páginas de la primera plana y los que se encuentran en los ángulos los de las páginas de la retiración 

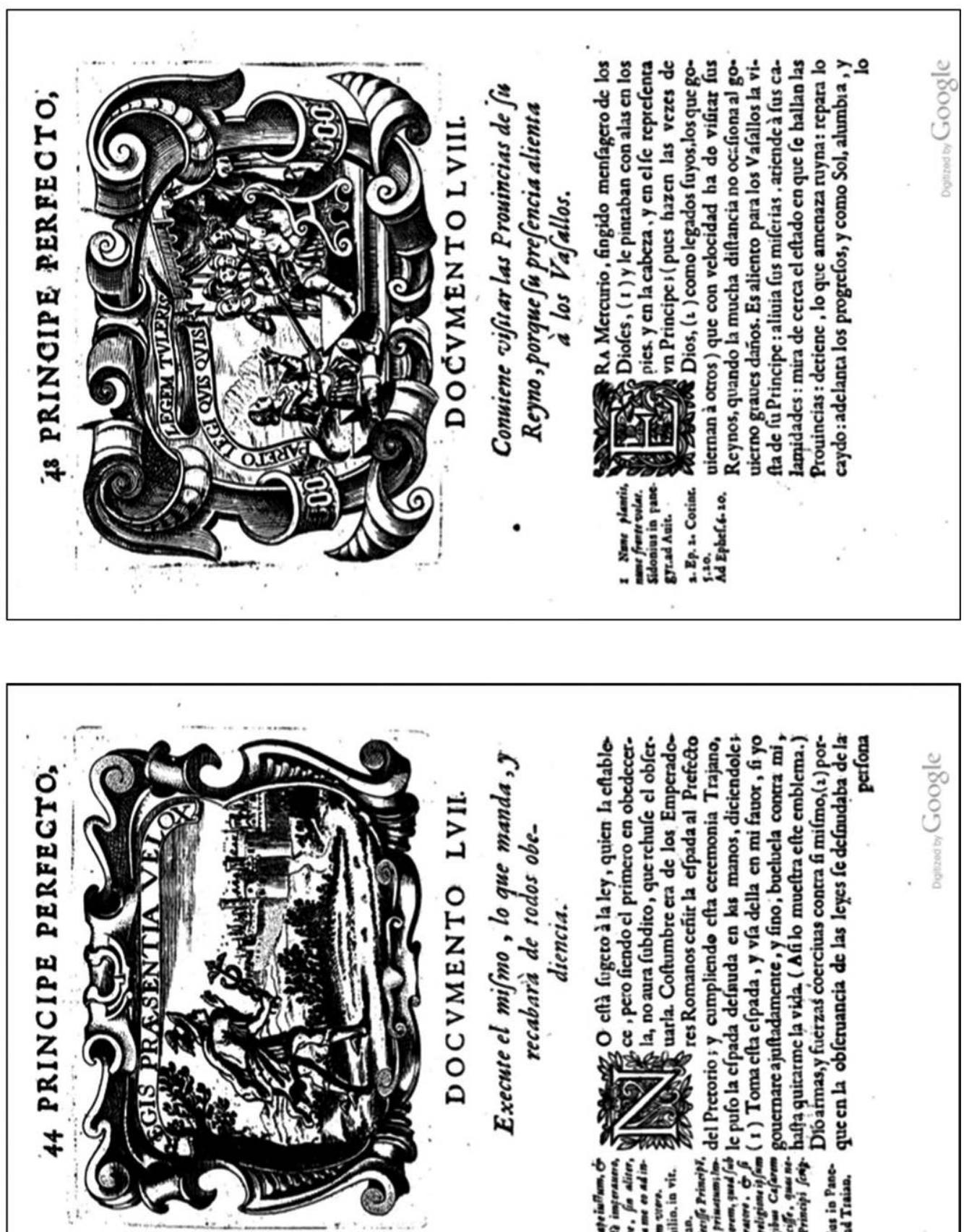

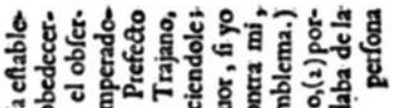
긍ํำ ส

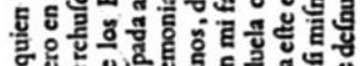
6.

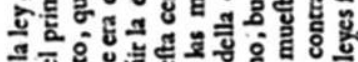

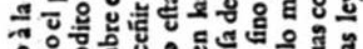

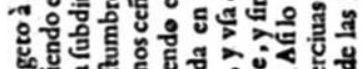

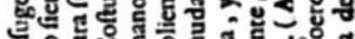
¿ี้ 证

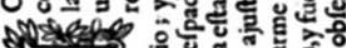

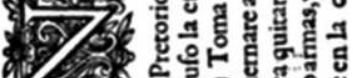

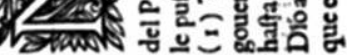
bำำ

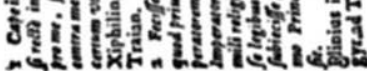

Fig. 6. - Páginas 44 y 48 del ejemplar Rés. 340882 de la Bibliothèque Municipale de Lyon 


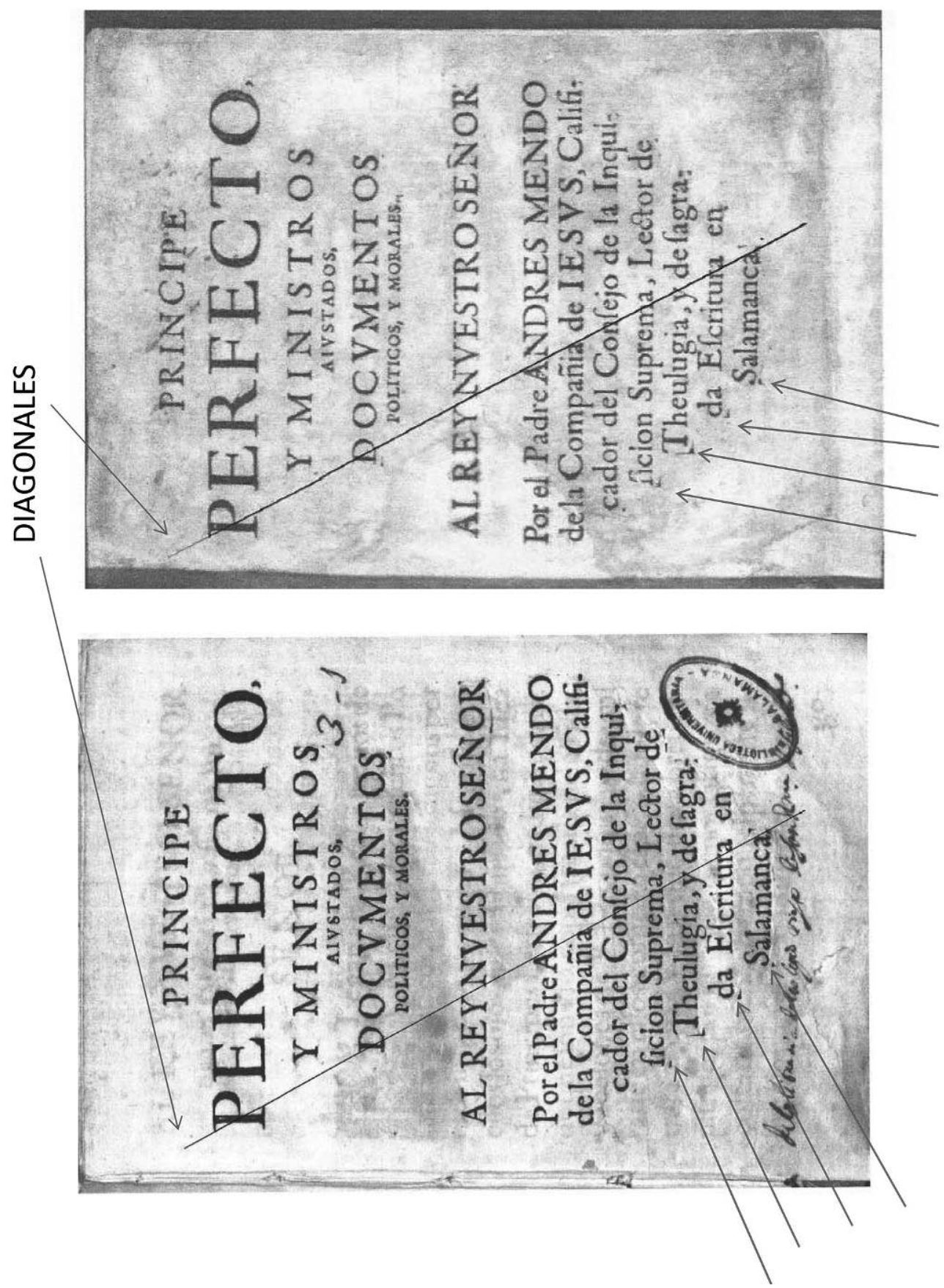

Fig. 7. - A la izquierda, portada de un ejemplar de la edición publicada en Salamanca en 1657. A la derecha, portada del ejemplar R/38475 de la Biblioteca Nacional de España, sin datos editoriales 


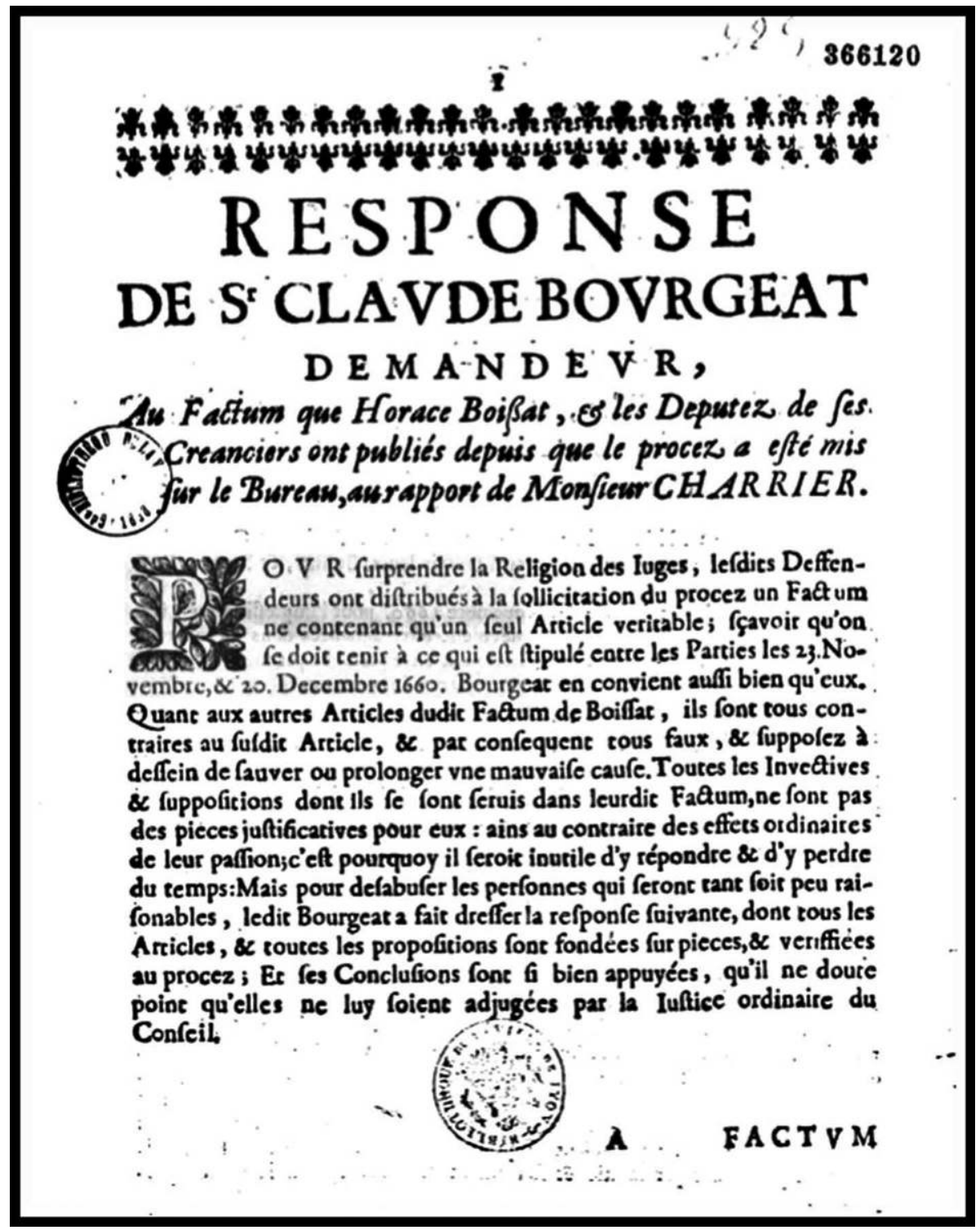

Fig. 8. - Portada del documento 366120 del fondo antiguo de la Bibliothèque Municipale de Lyon 


\section{Anexo I}

\begin{tabular}{|c|c|c|c|c|c|c|c|c|c|}
\hline & \multicolumn{9}{|c|}{ Ejemplares de la edición lionesa manejados } \\
\hline & \multicolumn{7}{|c|}{$\begin{array}{l}\text { Emisión A } \\
\text { [1662, } 2 \text { eds., dedicatoria de A. Mendo a Alonso } \\
\text { Pérez de Guzmán] }\end{array}$} & \multicolumn{2}{|c|}{$\begin{array}{l}\text { Emisión B } \\
\text { [1661, } \\
4 \text { eds., } \\
\text { dedicatoria } \\
\text { de C. } \\
\text { Bourgeat a } \\
\text { la Reina de } \\
\text { Francia] }\end{array}$} \\
\hline $\begin{array}{l}\text { Variantes y otras } \\
\text { particularidades }\end{array}$ & 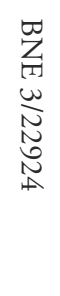 & 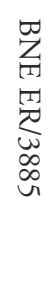 & 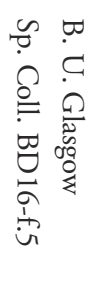 & 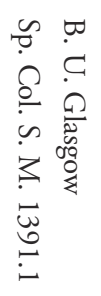 & 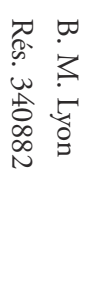 & 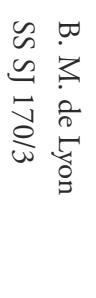 & 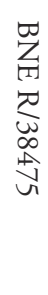 & 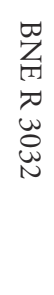 & 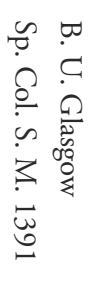 \\
\hline $\begin{array}{l}\text { Cuad. sign. ff: páginas } 42 \text { y } \\
43 \text { intercambiadas con } 46 \text { y } \\
47\end{array}$ & & & & & & & & $\mathrm{X}$ & \\
\hline $\begin{array}{l}\text { Cuad. sign. ff: documentos } \\
\text { LVII y LVIII con las picturae } \\
\text { intercambiadas }\end{array}$ & & & & & & & & $\mathrm{X}$ & \\
\hline $\begin{array}{l}\text { Cuad. sign. ff: Repetición } \\
\text { de la pictura del documento } \\
\text { LVIII en el documento LVII }\end{array}$ & & & & & & $\mathrm{X}$ & & & \\
\hline $\begin{array}{l}\text { Página sign. } \dagger 3 \text { r.: } \mathrm{N} \\
\text { mayúscula en la palabra norte }\end{array}$ & & & & & & & & $\mathrm{X}$ & \\
\hline $\begin{array}{l}\text { Página sign. } \quad+4 \quad \text { r.: } \\
\text { Recomposición en puntos } \\
\text { concretos }\end{array}$ & & & & & & & & $\mathrm{X}$ & \\
\hline $\begin{array}{l}\text { Cuad. sign. ff: recortes } \\
\text { para corregir el error en la } \\
\text { disposición de las imágenes } \\
\text { de los documentos LVII y } \\
\text { LVIII }\end{array}$ & & & & & & & & $\mathrm{X}$ & \\
\hline
\end{tabular}




\begin{tabular}{|c|c|c|c|c|c|c|c|c|c|}
\hline & \multicolumn{9}{|c|}{ Ejemplares de la edición lionesa manejados } \\
\hline & \multicolumn{7}{|c|}{$\begin{array}{l}\text { Emisión A } \\
\text { [1662, } 2 \text { eds., dedicatoria de A. Mendo a Alonso } \\
\text { Pérez de Guzmán] }\end{array}$} & \multicolumn{2}{|c|}{$\begin{array}{l}\text { Emisión B } \\
{[1661,} \\
4 \text { eds., } \\
\text { dedicatoria } \\
\text { de C. } \\
\text { Bourgeat a } \\
\text { la Reina de } \\
\text { Francia] }\end{array}$} \\
\hline $\begin{array}{l}\text { Variantes y otras } \\
\text { particularidades }\end{array}$ & 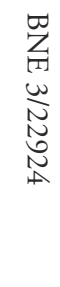 & 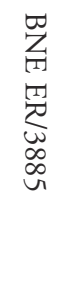 & 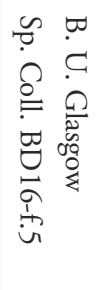 & 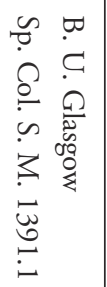 & 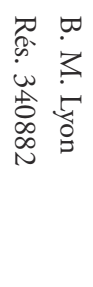 & 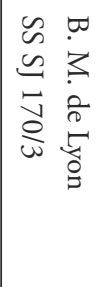 & 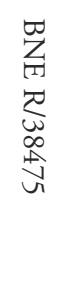 & 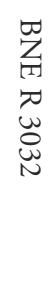 & 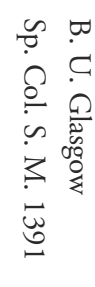 \\
\hline $\begin{array}{l}\text { Cuad. sign. ff: recorte del } \\
\text { grabado que corresponde al } \\
\text { documento LVII sobre el del } \\
\text { documento LVIII }\end{array}$ & & & & & & $\mathrm{X}$ & & & \\
\hline $\begin{array}{l}\text { Cuad. }{ }_{*}^{4},{ }_{* * *}^{4},{ }_{* * *}^{4}{ }^{4 * * * *}{ }^{2} \text { con el } \\
\text { «Índice de sentencias y cosas } \\
\text { más notables» situados al final }\end{array}$ & & $\mathrm{X}$ & $\mathrm{X}$ & $\mathrm{X}$ & & & & & $\mathrm{X}$ \\
\hline $\begin{array}{l}\text { Sustitución de la portada } \\
\text { original por la de la edición } \\
\text { de Salamanca, } 1657\end{array}$ & & & & & & & $\mathrm{X}$ & & \\
\hline
\end{tabular}

